\title{
Representación e historiografía: miradas múltiples al pasado de la Isla de Cubagua (1892-2014)
}

\author{
Representation and historiography: multiple looks to the past of the \\ Cubagua Island (1892-2014)
}

\author{
Fidel Rodríguez Velásquez* \\ fidelrodv@gmail.com \\ Maestría en Historia de las Américas \\ Universidad Católica Andrés Bello (UCAB) \\ Final Av. Teherán, Urb. Montalbán \\ Caracas, 1020, Apdo. 20.332 \\ Venezuela
}

\section{Resumen}

La isla de Cubagua ha sido representada en su pasado de múltiples maneras en la historiografía contemporánea, algunas veces como como sinónimo de Nueva Cádiz, otras veces como sinónimo de riqueza, explotación y catástrofes naturales. El presente trabajo constituye una aproximación a los discursos que sobre el pasado de la Isla de Cubagua se ha construido, para dar cuenta de las diversas miradas y enfoques, así como, de los diversos intereses que han orientado a los investigadores en la reconstrucción del pasado Cuagüense. Para ello se dividió la producción historiográfica en tres etapas. La primera de ellas denominada prospectiva, por el carácter pionero de los trabajos realizados en esta etapa, la segunda arqueológico-documental caracterizada por el papel de estas investigaciones en la producción de fuentes documentales y arqueológicas para el estudio del pasado de la Isla de Cubagua y la tercera como etapa interpretativa, pues en ella se dirigen los intereses de los investigadores a problemas específicos del pasado Cuagüense.

\section{Palabras clave}

Historia de América; Antropología histórica; Historiografía.

\begin{abstract}
Cubagua Island has been represented in the past in many ways in modern history, sometimes as synonymous with New Cadiz, sometimes as synonymous with wealth, exploitation and natural disasters. This work is an approach to the discourses on the past of Cubagua has been built, to account for the diverse perspectives and approaches, as well as the various interests that have guided researchers in the reconstruction of the past Cuagüense. For this historiographical production, it was divided into three stages. The first one called foresight, by the pioneering nature of the work carried out at this stage, the second archaeological documentary characterized by the role of these investigations in the production of documentary and archaeological sources for the study of the past in Cubagua and the third as an interpretive stage, because in it the interests of researchers target specific problems of the past Cuagüense.
\end{abstract}

\section{Keywords}

American History; Historical anthropology; Historiography.

Recibido el: 11/10/2016

Aceptado el: 4/2/2017

\footnotetext{
* Antropólogo egresado de la Universidad Central de Venezuela (UCV), en la actualidad cursa estudios de postgrado en Historia de las Américas en la Universidad Católica Andrés Bello (UCAB). Es investigador acreditado en la Categoría A2 por el Observatorio Nacional de Ciencia Tecnología e Innovación (ONCTI).
} 


\section{Representación e historiografía ${ }^{1}$}

Todas las sociedades, sean occidentales o no, poseen mecanismos de orden social que lespermiten representarse a sí mismas en su presente y su pasado, y por ende diferenciarse de otras sociedades generando de esta manera lo que podrían denominarse cartografías culturales en las cuales se define el adentro/ afuera y el nosotros/ellos que funda la construcción de identidades (AMODIO 1993). Estas representaciones no son estáticas, por el contrario revisarlas con profundidad histórica siempre permite observar y analizar las transformaciones que tienen lugar en esas representaciones y autorepresentaciones que pueden o no cambiar radicalmente dependiendo del periodo estudiado.

Cuando estudiamos estas representaciones del pasado en el caso específico de las sociedades occidentales, pueden tomarse dos caminos, el de las fuentes orales o el de la historia escrita, caminos que no necesariamente se encuentran separados, sino que por el contrario muchas veces se alimentan y realimentan constantemente entre sí. En el presente trabajo centraremos la mirada en un tipo específico de representaciones que tienen lugar sobre el pasado y es aquella que se hace desde las instituciones académicas, de esta forma analizaremos los discursos históricos sobre el pasado de la Isla de Cubaguacomo un tipo específico de producción cultural que se encuentra condicionada por los procesos de construcción de identidades de las sociedades presentes.

Asimismo, es necesario destacar que la multiplicidad de presentes desde los que se escriben los discursos históricos, muestran una diversidad de pasados, por lo que toda reconstrucción de carácter historiográfico debe necesariamente analizar la producción histórica considerando de manera específica las ideas, ideologías, intereses (académicos y políticos) y posturas de quienes son responsables de esta producción, para de esta forma poder valorar adecuadamente las contribuciones de cada uno a esa construcción del pasado, dejando siempre la posibilidad a que con nuevos datos o con nuevas miradas sobre los mismos datos puedan generarse mejores y más completas explicaciones sobre los procesos sociales que se aspiran estudiar.

La Isla de Cubagua se encuentra ubicada en el Mar Caribe, en conjunto con las islas de Margarita y Coche conforman el Estado Nueva Esparta de la actual República Bolivariana de Venezuela, la misma tiene una extensión territorial de $24,5 \mathrm{~km}^{2}$ y una extensión de costa de $26 \mathrm{~km}^{2}$, las máximas alturas de la isla no sobrepasan los $100 \mathrm{mts}$ de altitud. Esta porción de tierra en el mar entra en el escenario europeo a finales del siglo XV, específicamente en el año de 1498 cuando fue avistada por las naves que eran capitaneadas por Cristóbal Colon (OTTE 1977). Desde los primeros momentos de su encuentro con occidente, la isla de Cubagua paso a tener una importancia capital, puesto que en ella se estableció la explotación de los primeros bancos perlíferos en territorios americanos (PAYNE-IGLESIAS 2008). El encuentro de los marineros de Colon con los indígenas habitantes de la Isla de Cubagua es relatado por Fernández

\footnotetext{
${ }^{1}$ Quiero expresar mi agradecimiento al Arqueólogo Rodrigo Navarrete Sánchez y a la Antropóloga Julimar Mora por las discusiones sobre el pasado de la isla de Cubagua, muchos de los pasajes de este artículo fueron enriquecidos por esas discusiones.
} 
de Oviedo en su Historia General y Natural de las Indias señalando que una mujer con "una gran cantidad de hilos de aljófar" los intercambia por un "plato de los de Valencia" partido. Este relato da inicio a lo que podría denominarse "la época dorada de la isla de Cubagua" o al menos la de mayor importancia comercial desde el siglo XVI hasta la fecha. Las perlas de Cubagua llegaron a tener tanta importancia que se convirtieron durante los primeros momentos de colonización y conquista europea en territorios americanos en el principal rubro de exportación y llegaron a exhibirse como joyas en los vestidos y accesorios de los principales monarcas europeos, asimismo, estas joyas de la naturaleza fueron representadas e inmortalizadas en los cuadros del famoso pintor flamenco Theodor de Bry en sus serie titulada Grands voyages o Viajes a las Indias Occidentales (1590-1634) (BUENO JIMENEZ 1992).

En el pasado de la isla de Cubagua, hemos identificado tres etapas de la producción de los discursos históricos. La primera de ellas la hemos denominado etapa prospectiva (1892-1954) dedica a analizar los inicios del interés académico por el pasado de la Isla de Cubagua, la segunda arqueológico-documental (19551977), donde se realizaron los mayores aportes y se generaron las principales fuentes primarias con las que hoy en día se estudia el pasado de la Isla de Cubagua y una última etapa que hemos denominado interpretativa (19772014), ya no centrada en términos genéricos sobre la isla de Cubagua sino en problemas específicos vinculados a los diversos intereses de los investigadores.

\section{Etapa Prospectiva (1892 -1954): entre quimeras y realidades se entreteje el pasado de Cubagua}

El interés académico por el pasado de la Isla de Cubagua se inicia en Venezuela muy temprano a finales del siglo XIX, cuando en el año de 1892 el Dr. Arístides Rojas publica un artículo titulado El Escudo de Cubagua en el diario quincenal El Cojo Ilustrado en su volumen $n^{\circ} 6$ de fecha 15 de Marzo, en el reflexiona sobre la ciudad fundada por los españoles en esta pequeña Isla y sobre su importancia como la primera ciudad hispana erigida en los actuales territorios venezolanos, esta misma línea de reflexión será continuada por el autor en su columna Orígenes Venezolanos que será publicada el mismo año en los suplementos de este mismo diario. Posteriormente, en el siglo XX, específicamente, en el año de 1915 este interés se verá continuado con la visita a Venezuela del arqueólogo norteamericano Theodoor De Booy. Este investigador del Museum of American Indian vino con la intención de llevar adelante un proyecto general para conocer los restos de cultura material de los habitantes prehispánicos de Venezuela (DE BOOY 1916), la decisión de iniciar su proyecto en el oriente venezolano, específicamente en la Isla de Margarita estuvo muy ligada a la idea de reconstruir los primeros momentos del poblamiento de las Isla del Caribe considerando la proximidad de la Isla de Margarita con la Isla de Cubagua. Sin embargo, las dificultades de orden logístico circunscribieron sus primeras excavaciones a la Isla de Margarita y no a la Isla de Cubagua como era su idea inicial.

Sus excavaciones se realizaron específicamente en la zona noreste de la Isla de Margarita en la localidad de Girigire, donde se encontraron principalmente 
concheros y artefactos producidos con conchas, así como, restos óseos de humanos y mamíferos y un número considerable de fragmentos de vasijas con motivos antropomorfos y zoomorfos. No obstante, como señala el mismo autor también era común encontrar en casi todas las zonas de Margarita artefactos de piedra a través de la técnica de recolección superficial (DE BOOY 1916), especialmente, en las localidades de El Valle, la Asunción, San Antonio, Mosquito, Laguna Chica y la Sierra.

Sobre el trabajo de De Booy es importante señalar que se correspondía con el interés temprano de las instituciones académicas estadounidenses de tener un panorama completo sobre el pasado de las culturas prehispánicas americanas. La perspectiva de análisis encontrada en el trabajo de De Booy podría ubicarse dentro de lo que se denomina la Arqueología Tecnológica, es decir, una arqueología cuyo objeto central era el de definir los tipos de tecnología y comparar los hallazgos de producción de tecnológica de unos sitios con otros, para de esta forma establecer relaciones de cercanía o lejanía, por ello en el trabajo de De Booy no se encuentran inferencias de tipos etnológicas, así como tampoco reconstrucciones de las sociedades a partir de los restos de su cultura material.

Para ese momento no existía una tradición, ni una comunidad académica en Venezuela referente al estudio del pasado prehispánico, por lo que el trabajo de De Booy pasó de alguna manera inadvertido en el país. Sin embargo, tuvo un impacto importante en la incipiente comunidad arqueológica a principios del siglo XX, pues, las conclusiones de este trabajo permitían mostrar la existencia de un patrón tecnológico común en la Isla de Margarita, conclusiones que podían extenderse a la Isla de Cubagua y Coche, con las encontradas por el mismo autor en Santo Domingo, Cuba y Jamaica.

Posterior a este trabajo, el interés académicosobre el pasado de la Isla de Cubagua vendría del campo de la Literatura con la publicación de Enrique Bernardo Núñez de la novela Cubagua en el año de 1931.Cubagua viene a representar un esfuerzo importante por representar en este génerosus tesis histórico-historiográficas (STRAKA 2015) que sin lugar a dudas toman una distancia importante de la mirada que hasta el momento había sido dominante, la de la Venezuela Heroica (1881) de Eduardo Blanco. Cubagua viene a representar esa primera mirada al pasado venezolano en la que no destacan los grandes héroes a caballo ylas grandes hazañas militares por liberar las tierras americanas del llamado imperio español, por el contrario, Cubagua representa como señala Suarez (2014) "otra historia", la de la vida cotidiana, la de otros actores sociales distintos a las elites y los grandes héroes del ejercito patriota. En ella personajes como Arimuy, Fray Dionisio y Tiberio Mendoza, dan vida a una historia, en la cual, Núñez nos ofrece una particular visión sobre el pasado y el presente venezolano, pero escenificado en la Isla de Cubagua. El éxito de su novela fue tan importante que logrócolocar a la Isla en el imaginario de las elites letradas venezolanas, despertando de esta forma un interés importante sobre su presente y su pasado, sobre todo, por el papel de ciudad fundadora de la presencia hispánica en América, teniendo esto, importantes consecuencias en términos de la construcción de la identidad nacional. 
Volviendo al campo de las Ciencias Históricas, ${ }^{2}$ las primeras menciones al pasado de Isla de Cubagua tienen lugar en 1940 en trabajos muy generales y centrados en las ideas referentes a la desaparición de la ciudad de Nueva Cádiz realizados por Casto López en su libro La Margarita, Isla Venezolana de las Perlas y por Centeno Grau en su obra Estudios Sismológicos. Esta misma línea de trabajo continua en 1947con Julio Febres Cordero en su libro Hacia una nueva Geografía (VILA 1948). Posterior a esto se realizaron en el año de 1948 las primeras expediciones nacionales con las visitas realizadas a la Isla por Pablo Vila, quien, acompañado por el médico Italiano radicado en la población de Punta de Piedras Iscilio Crisci, Alfredo Boulton y sus estudiantes del Instituto Pedagógico de Caracas, estuvo realizando algunas prospecciones y recolecciones superficiales de restos de cultura material con el objetivo de demostrar que la Ciudad de Nueva Cádiz no había sido destruida por un terremoto sino por un huracán y por tanto aún seguía bajo tierra (OTTE 1977, p. 564). A partir de esta visita se iniciaron un conjunto de expediciones por parte de otros investigadores donde destacan las realizadas por Jesús Mata de Gregorio y el Lino Moulines, y por una comisión de la Universidad Central de Venezuela encabezada por Miguel Acosta Saignes donde también participaron el profesor José Antonio de Armas Chitty y nuevamente el profesor Jesús Mata de Gregorio (CRUXENT 1972).

A raíz de estas visitas vieron la luz los primeros trabajosrealizados con mayor especificidad sobre la Isla de Cubagua, nos referimos específicamente a los de Pablo Vila (1948), José de Armas Chitty (1951), Miguel Acosta Saignes 32 (1953; 1954) y José María Cruxent (1955). Este florecimiento de los trabajos académicos sobre el pasado de la Isla de Cubagua estuvo también caracterizado por una multiplicidad de intereses y de posturas teórico-epistemológicas por parte de los investigadores de las cuales, se desprenden claramente tres líneas de trabajo. La primera, donde se ubican tanto Pablo Vila como José de Armas Chitty, es decir, la historia tradicional caracterizada por el uso de fuentes documentales provenientes de los archivos, donde destaca el carácter narrativo de la historia a construir. Asimismo, es importante destacar la postura de ambos investigadores en relación al origen de la nación venezolana, puesto que Vila como Armas Chitty hacen un énfasis importante en igualar el pasado de Cubagua con el pasado de Nueva Cádiz para de esta forma,representar una historia de estos territorios que tendría su origen con la llegada de los españoles a América. Dentro de esta línea de trabajo destacan fundamentalmente dos temas que luego pasaran a formar parte del imaginario venezolano con respecto a la Isla de Cubagua: la extracción de perlas y la ciudad hundida por un cataclismo.

La segunda línea de trabajo se encuentra representada por Acosta Saignes quien, interesado en el pasado prehispánico, escribe el enigma de los Guaiqueríes como uno de los ensayos que forma su obra Estudio de Etnología Antigua, en ella, el autor ofrece una visión etnológica sobre el pasado de los habitantes de la Isla de Cubagua, discutiendo sobre su origen étnico y su adscripción lingüística, asimismo, ofrece una visión de conjunto respecto a lo que el denominaría la

2 Para profundizar en esta definición de ciencias históricas, ver Vargas Arenas (1986). 
zona Circuncaribe. Acosta Saignes construye esta visión a partir de fuentes documentales y relatos de los cronistas, la cual, se ve impregnada de teoría antropológica para buscar de esta forma lo que el mismo autor denomino la síntesis etnológica. Esta visión propuesta por Acosta Saignes ofrece por primera vez en Venezuela la posibilidad reflexionar el pasado prehispánico desde una perspectiva interpretativa donde no se generaliza a los habitantes prehispánicos en términos culturales, asimismo, el texto ofrece una visión sobre la importancia que el autor le da al pasado prehispánico en términos de la construcción de la identidad nacional y la formación de la venezolanidad, queda claro que para Acosta Saignes la historia de los territorios que en la actualidad conforman la República Bolivariana de Venezuela no comenzó con la colonización hispana en siglo XVI. Esta postura lo llevara tener una polémica importante con Arturo Uslar Pietri a través de artículos de prensa publicados por el Diario El Nacional durante la década de 1950 los temas centrales de esta polémica fueron la identidad nacional, el pasado prehispánico y la concepción de la historia.

La tercera línea de trabajo es la visión arqueológica representada por José María Cruxent, quien inicia sus trabajos de campo en la Isla de Cubagua en el año de 1954 en compañía del arqueólogo norteamericano John Goggin de la Universidad de Gainesville, ubicada en Florida. Los intereses de ambos investigadores eran muy diversos, Goggin tenía como idea central la de recolectar alfarería española, pues, se encontraba para ese momento realizando un proyecto continental sobre la mayólica española en territorio americano, en cambio los intereses de Cruxent eran más diversos puesto que estaba interesado tanto en la ocupación hispana, como en la presencia de materiales prehispánicos en la Isla. De estas primeras excavaciones arqueológicas son publicados unos resultados incipientes en la revista farol en el año de 1955 bajo el nombre de Nueva Cádiz, Testimonio de Piedra donde nuevamente se observa el interés por representar el pasado de Cubagua como el pasado de la Ciudad de Nueva Cádiz.

Esta primera etapa de la historiografía sobre la Isla de Cubagua la hemos denominado prospectiva, puesto que en ella se tienen lugar los primeros intereses sobre el pasado de la Isla y ven la luz las primeras publicaciones que de una u otra manera trazarían desde diversas perspectivas lo que sería el futuro de los estudios sobre el pasado de la Isla de Cubagua.

\section{Etapa Arqueológico - Documental (1955 - 1977): entre tiestos y textos aflora el pasado de la Isla de Cubagua}

\section{Lo que dicen los tiestos...}

Esta segunda etapa inicia con la continuación de las excavaciones arqueológicas realizadas en la Isla de Cubagua por parte de Cruxent y Goggin, donde el hallazgo de una vasija llena de perlasobtuvo una notoriedad importante por los medios de comunicación de la época, lo cual, tuvo dos consecuencias importantes, la primera de ellas alimentar el imaginario de la sociedad venezolana con respecto a la Isla de Cubagua y la Ciudad de Nueva Cádiz como un lugar 
Ileno de riquezas y el segundo, que el gobierno nacional proveyera los fondos necesarios para que Cruxent ampliara y continuara sus excavaciones en la isla.

Esta ampliación de los trabajos arqueológicos permitió una división más clara del trabajo y de los intereses, mientras Goggin continúo excavando las ruinas de la Ciudad de Nueva Cádiz ubicada en la zona este de la Isla de Cubagua, Cruxent en compañía de otro arqueólogo norteamericano llamado Irving Rouse excavo diferentes lugares de la Isla ubicando tanto sitios prehispánicos, como sitios que denomino indohispánicos por la coexistencia de material indígena con material hispánico.Las excavaciones en la antigua ciudad de Nueva Cádiz permitieron reconstruir gran parte del trazado de la ciudad y la recuperación de gran cantidad de materiales de uso diario de las personas que ahí habitaban, entre ellos: porcelanas, vidrios, metales azulejos e incluso, el escudo y un par de gárgolas pertenecientes al antiguo convento de San Francisco, también se encontraron otros artefactos de cerámica y adornos que indicarían la presencia en la Isla de indígenas provenientes de tierra firme y otras islas del caribe, muy probablemente, con el objetivo de ser utilizados como mano de obra en la extracción perlífera (MOLINA 1998).

Los resultados de estos trabajos fueron publicados en los años de 1959 por Cruxent en un texto titulado An archeological chronology of Venezuela y posteriormente, en 1963 en otro texto tituladoVenezuelan Archeology en coautoría con Irving Rouse. Por otro lado, Goggin public en 1968 Spanish Majolica in the New World: Types of the 16th to 18th Centuries. Las principales conclusiones de los trabajos de Cruxent y Rouse respecto al pasado prehispánico de la Isla de Cubagua apuntan a siete ocupaciones sucesivas en la zona, cuya evidencia se encuentra en 5 complejos divididos en dos grupos, un primer grupo conformado por los complejos Cubagua (4.320 - 3.725 años Antes del Presente), Manicuare (3.725 - 1.895 años AP) y Punta Gorda (1.895 - 1.580 años AP)pertenecientes a la Serie Manicuaroide que son considerados como complejos precerámicos. Esta serie se define a partir de la presencia de puntas de hueso, gubias de concha y la piedra de dos puntas. En el segundo grupo se encontró material de origen hispánico e indígena, si bien, el mayor grupo de este material son las llamadas Ruinas de la Ciudad de Nueva Cádiz o complejo Nueva Cádiz (500 años A. P), también es importante mencionar al complejo Obispo (500 años AP).En el caso del trabajo de Goggin, Spanish Majolica in the New World: Types of the 16th to 18th Centuries, permitió identificar las diversas rutas de entrada de la mayólica española en el continente americano, siendo una de las primeras rutas utilizadas a principios del siglo XVI la Isla de Cubagua.

También es importante resaltar las características de la arqueología practicada por Goggin, Rouse y Cruxent, la cual, podría ubicarse con una gran influencia europea, específicamente, de la escuela historicista que se encontraba en pleno apogeo. Esta escuela de pensamiento privilegiaba una "Visión artefactual y descriptiva que pretendía ofrecer una síntesis cronológica cultural a través de la definición estilística artefactual" (NAVARRETE SÁNCHEZ 2010, p. 130) de esta forma, tiene mucho peso para estos autores la estratigrafía, la descripción y la definición de complejos y series; en cambio, se encuentra una ausencia total de 
propuestas etnológicas que permitan ahondar su relación con la cultura material y los grupos étnicos del presente y del pasado. También es importante destacar la influencia que tuvieron los autores de la arqueología norteamericana, pues, en el momento en que estos se encontraban realizando sus excavaciones se estaba también gestando una importante escuela de pensamiento conocida como arqueología histórica, la cual, reivindica el papel de la arqueología en la construcción de las representaciones y discursos históricos que servirán de soporte para la construcción de identidades nacionales y de lo que se ha denominado los usos políticos del pasado.

\section{Papeles viejos ¿Qué dijeron los documentos?}

Posterior a los trabajos arqueológicos, a principios de los años 60 comienzan a materializarse los esfuerzos de la fundación John Boulton por la reconstrucción del pasado de la Isla de Cubagua, en el verano de ese año su presidente Alfredo Boulton invita al historiador español Enrique Otte a Venezuela y lo contrata para escribir una historia de la Isla de Cubagua (OTTE 1977), pero dicha historia, no podría ser escrita sin un importante trabajo de recolección de documentos antiguos en el Archivo de Indias ubicado en Sevilla, labor de la que prontamente se ocupó el historiador.

Es por ello que para el año de 1961 vería la luz los primeros esfuerzos, con la publicación del Cedulario de la monarquía española relativo a la Isla de Cubagua, ${ }^{3}$ el cual constituye hasta el día de hoy el intento más importante por reunir en una sola publicación todas las cedulas reales referentes a la Isla de Cubagua que se conservaron en las distintas secciones del Archivo General de Indias, en total se recogen 427 cedulas reales transcritas como señala el mismo Otte utilizando el método comúnmente aceptado para la época en Venezuela.

En esta misma década, pero en el año de 1967 sería publicado otro importante trabajo donde se incluiría una sección dedicada a la Isla de Cubagua, nos referimos al trabajo de Pablo Ojer La formación del Oriente Venezolano ${ }^{4}$ el cual se nutre tanto de los cedularios recogidos por Otte como de la importante colección de documentos trasladadas por el mismo y por Herman González Oropeza al Instituto de Investigaciones Históricas de la Universidad Católica Andrés Bello (UCAB) a partir de los índices de los documentos relativos a Venezuela ubicados en el archivo General de Indias elaborados por el Hno. Nectario María. Esta colección de documentos proviene del Archivo General de Indias (Sevilla), el British Museum (Londres), el Public Record Office (Londres), Bodleian Library (Oxford), Archives Nationales (Paris), Archivos General de Simancas (Valladolid), el Archivo Nacional y la Biblioteca Nacional (Madrid). El trabajo de Ojer puede considerarse como un trabajo pionero en la zona, al punto que élmismo señala que la historia del oriente de Venezuela, se encuentra en muchos aspectos "donde la dejaron los cronistas", asimismo, también es importante señalar la amplitud del marco geográfico y

\footnotetext{
3 Publicado en el año de 1961 en una edición conjunta entre la Fundación John Boulton y la Fundación Eugenio Mendoza Quintero.

${ }^{4}$ Este trabajo fue presentado como tesis doctoral por Pablo Ojer ante la Universidad Javeriana de Colombia y publicado por la Universidad Católica Andrés Bello.
} 
temporal de la investigación del profesor Ojer puesto que abarcó todo el siglo XVI y los territorios que van desde Piritu hasta Guayana, incluyendo las Islas que en la actualidad conforman el estado Nueva Esparta nos referimos a Margarita, Coche y Cubagua. El aspecto central del trabajo está referido a la creación de las gobernaciones como primeras instituciones hispanas en el continente.

Una década más tarde, en 1977, sería publicado el trabajo de Enrique Otte tituladolas Perlas de Caribe: Nueva Cádiz de Cubagua, en el cual el autor recoge los resultados de años de investigación dedicados a los documentos que la monarquía española expidió para la Isla de Cubagua, se trata de un trabajo minucioso en el que se analiza el auge y caída de la ciudad de Nueva Cádiz como asentamiento español y su relación con la explotación de las perlas en las primeras cuatro décadas del siglo XVI. La obra de Otte ofrece una visión de conjunto sobre la sociedad hispana que tiene lugar en la Isla de Cubagua, pero siempre manteniendo cada aspecto de la vida social en articulación con la explotación perlífera, el trabajo se divide en dos partes, la primera de ellas titulada Las perlas del caribe, donde el autor sitúa a Cubagua y su importancia en el escenario mundo del siglo XVI y una segunda parte titulada Nueva Cádiz de Cubagua, en la que Otte se pasea minuciosamente por esta sociedad donde como el mismo señalada la perla, ese pequeño tesoro producto de la introducción de cuerpo extraño en el interior de un molusco bivalvo denominado Pteria, lo significó todo.

Estos dos trabajos constituyen los trabajos históricos más importantes 36 publicados referentes al pasado de la Isla de Cubagua, asimismo, es importante resaltar el significativo trabajo de recolección documental hecho por los autores, al punto que en la actualidad tanto los documentos recopilados por Otte como por Ojer en los archivos europeos continúan siendo los fondos documentales más importantes que se tienen en Venezuela para estudiar los primeros momentos de la presencia hispana en el continente y por lo tanto son de obligatoria consulta para quien emprenda una investigación de este periodo tan importante y al mismo tiempo tan poco estudiado. Es por ello que a la hora de valorar la importancia de estos dos trabajos para la historiografía venezolana y en particular para la historiografía cuagüense y oriental, no dudamos en catalogarla de muy significativa, no solo por las dimensiones y lo minucioso de sus trabajos si no porque sus recopilaciones documentales pusieron al alcance de muchos investigadores interesados en estos temas las fuentes primarias para muchos estudios que incluso en la actualidad aun estar por hacerse.

A modo de cierre de esta etapa que hemos catalogado de arqueológicodocumental y hemos ubicado temporalmente entre 1955 y 1977, podríamos decir que ha dado los frutos más importantes hasta la actualidad en cuanto a la reconstrucción del pasado de la Isla de Cubagua, puesto que el carácter general y pionero tanto de las investigaciones arqueológicas como documentales realizadas significaron la apertura de grandes líneas de trabajo y dejaron para el futuro la posibilidad de dar cabida a nuevas miradas y nuevos enfoques sobre problemas específicos que la amplitud de estas obras no pudo y no tenía como objeto resolver. 


\section{Etapa Interpretativa (1977 - 2014): Cubagua nuevos retos, nuevas miradas}

La década de los 80 significó un vacío en cuanto a la producción historiográfica sobre el pasado de la Isla de Cubagua, pareciera que la comunidad académica necesitó de una década para digerir el ampliamente sustentado trabajo de Enrique Otte, no será hasta finales de esa década cuándo volverán a ver la luz investigaciones referentes al pasado cuagüense, pero esta vez desde la arqueología, con los aportes de Mario Sanoja Obediente (1989) con el trabajo titulado Origins of Cultivation around the gulf of Paria, North eastern Venezuela, donde a partir de las excavaciones del sitio La Aduana, ubicado en la Isla de Cubagua, y los sitios Manicuare, Indismo, Laguna Grande, Las Varas, No Carlos, Remigio y Guayana ubicados en el norte del estado Sucre, y su posterior análisis en relación con los cambios ecológicos dentro de los cuales se encuentran la aparición de ambiente de manglar y las fluctuaciones en el nivel del mar del mar. Las principales conclusiones del trabajo de Sanoja Obediente apuntan a una importante transformación de la economía, la tecnología y la organización social de los grupos que habitaban esta zona con el fin de sacar provecho delas cambiantes condiciones ecológicas de finales del pleistoceno, dentro de estos cambios el autor menciona la creación de enclaves sedentarios o semisedentarios para adquirir y procesar los alimentos; la explotación estacional de recursos naturales; la iniciación de la pesca y la recolección especializada en lagos, mares y ríos; así como, desarrollos tecnológicos tales como arcos y flechas, arpones, redes de pesca, anzuelos, embarcaciones y la navegación, gubias para trabajar madera y hachas y azuelas para limpiar y preparar los campos para el cultivo.

El principio de la década de los años 90 coincidió con la llamada "celebración" de los 500 años de la presencia europea en los territorios americanos impulsada por la Agencia de Cooperación Internacional Española y algunos gobiernos latinoamericanos, en este marco tuvo lugar una polémica muy importante sobre el presente, el pasado y el futuro de la Isla de Cubagua a raíz de los inicios de un proyecto turístico que buscó convertir a la Isla en un gran complejo con hoteles 5 estrellas y campos de golf. Los preacuerdos entre el Estado venezolano y una compañía transnacional desataron la polémica, por paradójico que parezca, las principales herramientas utilizadas por quienes adversaban el megaproyecto turístico fueron precisamente las Investigaciones tanto de José María Cruxent como de Enrique Otte, dando esto una prueba importante de los usos políticos del pasado, esta vez como arma para defender lo que en ese entonces sus líderes consideraban el derecho de los margariteños y los venezolanos a ser dueños de lo que fue la primera ciudad hispana en Venezuela, a raíz de este movimiento vio la luz un pequeño libro titulado Cubagua: un llamado a la conciencia nacional (1991) cuyo autor fue el historiador Iván Gómez, la polémica se saldó en un debate nacional en el antiguo congreso de la republica que terminaría por prohibir el megaproyecto hotelero.

Posteriormente, el interés sobre el pasado cuagüense, continuó con la aparición de dos trabajos importantes, nos referimos específicamente a la investigación de María Ángeles Eugenio (1992) titulada Una empresa de perlas: los Barrera en el caribe centrada en historiar la familia Barrera como actores 
clave en el comercio de perlas y el trabajo realizado por Reitz (1993) The spanish colonial experience and domestic animalsdonde se analiza la experiencia española en la introducción de animales europeos en las islas de la Hispaniola, Cubagua y Florida. Estos dos trabajos, así como, el de Sanoja Obediente (1989) muestran un cambio importante en la forma de los investigadores de acercase a los problemas sobre le pasado cuagüense, mientras en la etapa anterior las investigaciones tenían una mirada totalista, en esta etapa se busca dar respuesta a problemas específicos sobre el pasado de la Isla de Cubagua.

Para el año de 1995 Sanoja Obediente y Vargas Arenas publicarán Gentes de la Canoa, donde ofrecerán una nueva interpretación acerca del pasado Cuagüense, pero esta vez desde la perspectiva de la arqueología social latinoamericana. ${ }^{5}$ De esa manera los conceptos bajo los cuales se llevó adelante la interpretación del pasado fueron los de modo de vida, procesos productivos, modo de trabajo y fuerzas productivas para dar cuenta en última instancia de la sociedad que habitó la Isla de Cubagua. Las principales conclusiones de este trabajo señalan la preferencia de los antiguos pobladores de Cubagua por la navegación de alta mar, la recolección de moluscos marinos y el trueque de mercancías como sal, con grupos que habitaban las cosas de los actuales territorios de Venezuela. Sus principales industrias de manufactura estuvieron basadas en el procesamiento de madera, fibras, conchas y piedras. Asimismo, en términos de relaciones sociales, el registro estratigráfico muestra una serie sucesiva de ocupaciones que se van complejizando por el aumento de la intensidad de la explotación de los recursos marinos y por el aumento de la densidad poblacional. Otra de las conclusiones más importantes es la referente a las condiciones para establecer la vida social a partir del desplazamiento constante entre las islas, generando de esta forma itinerarios de viaje cíclicos asociados al desplazamiento de las fuentes de alimentos.

Un año después se publica el trabajo de Ayala Lafee (1996) La Etnohistoria Prehispánica Guaiquerí, dando continuidad al interés sobre los grupos étnicos que habitaron las islas de Margarita, Coche y Cubagua, en este trabajo la autora ofrece una visión de conjunto donde por primera vez se busca lograr una síntesis interpretativa a partir de los datos arqueológicos, los relatos de los primeros viajerosy los documentos oficiales de la época. Construyendo de esta forma una visión etnológica del pasado del pueblo Guaiquerí donde la Isla de Cubagua juega un papel central.

En esta misma década se inicia la producción historiográfica de Fernando Cervigón, ${ }^{6}$ cuyos intereses dieron sus frutos en tres publicaciones, Cubagua 500 años (1997), La Perla (1997) y Las Perlas en la historia de Venezuela (1998),

\footnotetext{
${ }^{5}$ La arqueología social latinoamericana, es una corriente de pensamiento dentro del campo de la arqueología que aspira a la compresión científica del pasado a partir de la aplicación de los conceptos del marxismo, tiene su origen en el año de 1976 con los intelectuales latinoamericanos que integraron el grupo de Teotihuacán, para conocer en mayor profundidad sobre esta corriente, ver Lumbreras (1976); Sanoja Obediente y Vargas Arenas (1992) y Navarrete Sánchez (2007).

${ }^{6}$ Fernando Cervigón proviene originalmente del campo de la biología marina y durante más de veinte años cultivo una estrecha relación con la Isla de Cubagua y especialmente con los pescadores con quienes convivio en largas temporadas mientras realizó sus trabajos de ictiología de donde se publicaron los ocho volúmenes que componen la obra de Los peces marinos de Venezuela, como el mismo señala, de estas largas estadías en la Isla proviene su interés por la historia de esta pequeña porción de tierra.
} 
cuya valor fundamental radica en el carácter divulgativo y educativo que las mismas tuvieron, la obra del Dr. Cervigón tuvo un importante impacto en las escuelas margariteñas donde volvió a reposicionar el interés por el pasado de la Isla de Cubagua y su valor patrimonial.

Volviendo nuevamente a la mirada etnológica, Silva Suniaga (2006) realizó una importante investigación a partir de los relatos de los cronistas de indias sobre la etnicidad de los habitantes de las Islas de Cubagua, Margarita y Coche que tituló Los Guaiqueríes: el enigma de un pueblo. Más recientemente destacan los trabajos de investigación realizados sobre el pasado de la Isla de Cubagua por investigadores europeos y norteamericanos, dentro de estos se puede mencionar los realizados por Tardieu (2008) Perlas y piel de azabache. El negro en las pesquerías de las indias occidentales donde diserta sobre el papel de los esclavos africanos en la extracción de perlas, así como las redes comerciales que se tejieron entorno a estos; el de Michael Perri (2009) Ruined and Lost: Spanish Destruction of the Pearl Coast in the Early Sixteenth Century donde basado en los trabajos de Ojer y Otte ${ }^{7}$ el autor centra su mirada en el daño al medio ambiente, la esclavitud y la desaparición de las poblaciones que para el momento habitaban la isla.

En los últimos 5 años se han publicado 3 artículos sobre el pasado de la Isla de Cubagua, uno de Alfredo Bueno Jiménez(2012) quien vuelve a centrar su mirada en el negocio de la explotación perlífera en su texto La granjería de Perlas en el nuevo mundo y dos de Molly Warsh quien escribió Enslaved Pearl Divers in the Sixteenth Century Caribbean (2010) y A political ecology in the early spanish caribbean (2014), el primero de ellos referido al tema de los esclavos dedicados al rescate de perlas y el segundo a comprender aspectos de las ecología política vinculados al rescate de perlas en las granjerías hispanas, dando una preponderancia importante a la propia comprensión de los habitantes sobre la necesidad de preservar su ambiente.

Esta última etapa de la producción historiográfica sobre el pasado de la Isla de Cubagua tiene como característica central la hiperespecialización de los temas de estudio, así como, un cambio en la perspectiva de estudio, no son nuevas fuentes documentales ni nuevas excavaciones arqueológicas lo que ha posibilitados nuevas formas de entender y comprender el pasado de la Isla de Cubagua, sino por el contrario, las nuevas investigaciones sobre el pasado cuagüense han sido posibles por aplicar nuevos enfoques y nuevas perspectivas sobre los datos y las fuentes que se tenían.

\section{Consideraciones finales}

Esta aproximación al estudio de la historiografía sobre la Isla de Cubagua, ha permitido un recorrido por los diversos intereses de los investigadores que sobre ella han centrado su mirada y ha hecho posible comprender las diversas valoraciones y representaciones que sobre la isla de Cubagua se han configurado, 
así hemos sido testigos de una Cubagua hispánica, la de la Ciudad de Nueva Cádiz, aquella donde tienen lugar los relatos históricos más conocidos sobre el pasado cuagüense compuestos fundamentalmente de perlas, esclavitud y desastres naturales. Sin embargo, antes y después de estos relatos más conocidos como nos muestra Acosta Saignes, José María Cruxent, Mario Sanoja Obediente, Iraida Vargas, Ayala Lafee y Silva Suniaga existió una Cubagua diferente, una Cubagua donde las puntas de huesos, los artefactos líticos y las gubias de conchas marinas componen sus vestigios más prominentes, como testigos de una sociedad diferente que con sus transformaciones aún persiste en algunas comunidades de la región insular.

Este recorrido historiográfico muestra muchas historias de Cubagua, incluso muchas de ellas aun no escritas, sin embargo, una valoración justa nos permitiría afirmar que todas y cada una de ellas aportan una dimensión, un interés, una mirada particular, por lo que toda producción histórica debe valorarse en su justa medida como una aproximación al conocimiento específico de un segmento de la historia cuagüense, teniendo siempre conciencia de que el futuro muy probablemente abrirá paso a nuevas fuentes, a nuevos enfoques o simplemente nuevas realidades del presente desde donde se escribe la historia que permitirán nuevos intereses y nuevas conclusiones sobre el pasado.

\section{Referencias bibliográficas}

ACOSTA SAIGNES, Miguel. Zona Circuncaribe: periodo indígena. México: Instituto panamericano de Geografía e Historia, 1953.

. El enigma de los Guaiqueríes. In: Estudios de Etnología Antigua de Venezuela. La Habana: Casa de las Américas, 1961, p. 171-187.

AMODIO, EMANUELE. Formas de la alteridad: construcción y difusión de la imagen del indio americano en Europa durante el primer siglo de la conquista de América. Quito: Editorial Abya Yala, 1993. v. 6.

ARMAS CHITTY, José. Origen y Formación de algunos pueblos de Venezuela. Caracas: Tip. Americana, 1951.

AYALA LAFEE, Cecilia. La etnohistoria prehispánica Guaiquerí. Antropológica, v. 82, 1996.

BUENO JIMÉNEZ, Alfredo. La "Granjería de las perlas" en el Nuevo Mundo. Cuadernos Americanos, v. 142, p. 83-111, 2012.

CERVIGÓN, Fernando. Cubagua 500 años. Caracas: Fundación Museo del Mar, 1997.

La perla. Pampatar: FONDENE, 1997.

. Las perlas en la historia de Venezuela. Caracas: Fundación Museo del Mar.1998.

CRUXENT, José María. Nueva Cádiz, testimonio de piedra. El Farol, n. 160 p. 2-5, 1955. 
An archeological chronology of Venezuela. Washington: Pan American Union, 1959.

- Algunas noticias sobre Nueva Cádiz (isla de Cubagua) Venezuela.

Memorias de la VI Conferencia Geológica del Caribe. Margarita, Venezuela, p. 33-35, 1972.

CRUXENT, Jose Maria; ROUSE, Irving. Arqueología cronológica de Venezuela. Caracas: Armitano, 1982. v. I-II.

DE BOOY, Theodoor. Notes on the archeology of Margarita Island, Venezuela. Contribution from de Museum of the American Indian. New York: Heye Foundation, 1916.

EUGENIO, María. Una empresa de perlas: Los Barrera en el Caribe. Actas XI jornadas de Andalucía y América, p. 9-37,1992.

GOGGIN, John. Spanish majolica in the New World: types of the sixteenth to eighteenth centuries. Haven: Yale University Press,1968.

GÓMEZ, Iván. Cubagua: un Ilamado a la conciencia nacional. Caracas: Editorial Abrebrecha, 1991.

LUMBRERAS, Luis Guillermo. La Arqueología como Ciencia Social. Lima: Ediciones Hista, 1974.

MOLINA, Luis. Cubagua: patrimonio histórico y cultural de Venezuela y América. Caracas: Instituto de Patrimonio Cultural,1998.

NAVARRETE SÁNCHEZ, Rodrigo. La Arqueología social latinoamericana: una meta, múltiples perspectivas. Caracas: Cuadernos CODEX - FaCES Universidad Central de Venezuela, 2007.

El cacique imaginado: Miguel Acosta Saignes y los modelos de complejidad social para la Venezuela prehispánica. Revista Venezolana de Economía y Ciencias Sociales, v. 16, n. 1, p. 129-143, 2010.

OJER, Pablo. La Formación del Oriente Venezolano. Caracas: Universidad Católica Andrés Bello,1966.

OTTE, E. Cedularios de la monarquía española relativos a la Isla de Cubagua (1523-1550). Caracas: Fundación John Boulton y Fundación Eugenio Mendoza, 1961.

. Las perlas del Caribe: Nueva Cádiz de Cubagua. Caracas: Fundación John Boulton, p. 564,1977.

PAYNE-IGLESIAS, Elizeht. Las perlas de la reina: explotación perlífera en el Pacífico de Centroamérica (1522-1850). Diálogos - Revista electrónica de Historia, n. esp., p. 631-654, 2008.

PERRI, Michael. Ruined and Lost': Spanish Destruction of the Pearl Coast in the Early Sixteenth Century. Environment and History, v. 15, n. 2, p. 129161, 2009. 
REITZ, Elizabeth. The Spanish colonial experience and domestic animals. Historical Archaeology, v. 26, p. 84-91, 1993.

ROJAS, Aristides. El Escudo de Cubagua. El Cojo Ilustrado, v. 6, 15 mar. 1892.

ROUSE, Irving; CRUXENT, Jose Maria. Venezuelan archaeology. New Haven: Yale University Press,1963. v. 6.

SANOJA, Mario. Origins of Cultivation around the Gulf of Paria, Northeastern Venezuela. National Geographic Research, v. 5, n. 4, p. 446-458, 1989.

SANOJA, Mario; VARGAS ARENAS, Iraida. Antiguas formaciones y modos de producción venezolanos. Caracas: Monte Ávila Editores, 1978.

- Gente de la Canoa. Economía Política de la Antigua Sociedad Apropiadora del Noreste de Venezuela. Caracas: Fondo Editorial Tropykos - Comisión de Estudios de Postgrados - FaCES, Universidad Central de Venezuela, 1995.

SILVA SUNIAGA, Juan. Los Guaiqueríes: el enigma de un pueblo. Caracas: El Perro y la Rana, 2006.

STRAKA, Tomas. Enrique Bernardo Núñez y las tramas de la Historia. In: ARRÁIZ LUCCA,Rafael; HERNÁNDEZ DELFINO, Carlos (Comp.). 25 intelectuales en la Historia de Venezuela. Caracas: Fundación Bancaribe, 2015, p. 257-266.

SUAREZ, Carlos. Arqueología, representación y patrimonio: las otras historias de Cubagua y Nueva Cádiz. Revista Nuestro Sur, n. 8, p. 41-57, 2014.

TARDIEU, Jean Pierre. Perlas y piel de azabache. El negro en las pesquerías de las Indias Occidentales. Anuario de Estudios Americanos, v. 65, n. 2, p. 91-124, 2008.

VARGAS ARENAS, Iraida. Arqueología, ciencia y sociedad. Boletín de antropología americana, v. 14, p. 5-52,1986.

VILA, Pablo. ¿La destrucción de Nueva Cádiz Terremoto o huracán? Boletín de la Academia Nacional de la Historia, v. 31, n. 123, p. 213-219, 1948. - Margarita en la Colonia, 1492-1550: los comienzos del poblamiento. Revista Nacional de Cultura, año 11, n. 81, p. 59-85, 1950.

. Las Actividades Perlíferas y sus vicisitudes en Venezuela. Revista de Historia, año III, n. 17, p. 13-3, 1963.

WARSH, Molly. Enslaved Pearl Divers in the Sixteenth Century Caribbean. Slavery and Abolition, v. 31, n. 3, p. 345-362, 2010.

. A political Ecology in the early Spanish Caribbean. William and Mary Quarterly, s. 3, v. 71, n. 4, p. 517-548, 2014. 